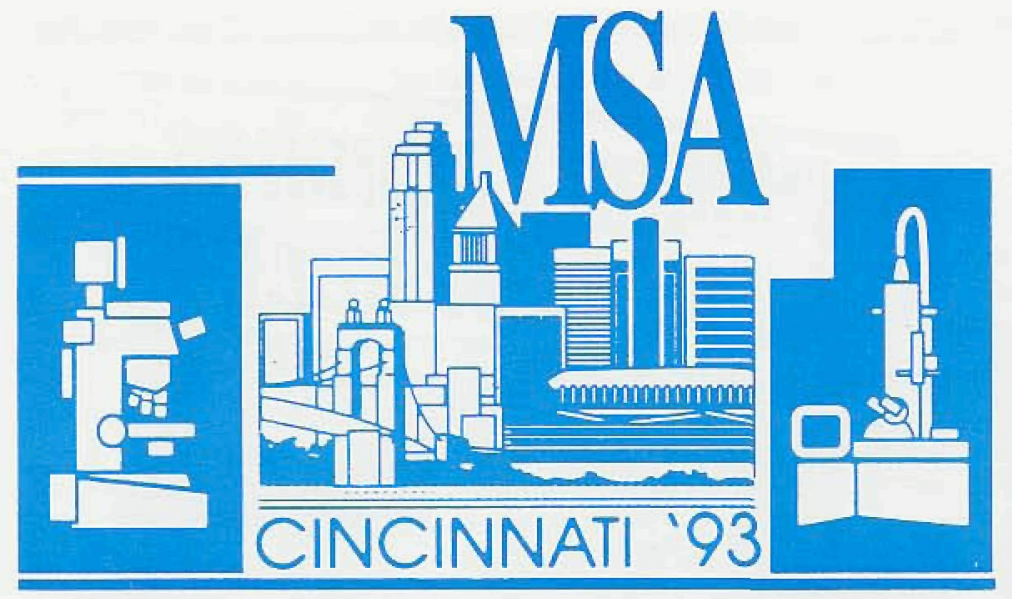

\title{
51st Annual Meeting Microscopy Society of America
}

\author{
Cincinnati Convention Center \\ Cincinnati, Ohio \\ August 1 - 6, 1993
}

Cincinnati is a friendly and vibrant river city and an ideal convention spot, centrally located in the U.S. with direct airline connections to numerous cities around the world. The large, attractive Dr. Albert B. Sabin Convention Center is connected by a covered walkway to all the convention hotels in the hea of Cincinnati's lively downtown area on the banks of the Ohio River, where the Public Landing, the Serpentine Wall, and Bicentennial Commons are enjoyed by sightseers, sunbathers, music lovers, joggers and steamboat watchers. You will find that most of Cincinnati's attractions are easy to get to and easy to enjoy. The integration of the Convention Center Skywalk with more than 3,000 hotel rooms, department stores, banks, cinemas, restaurant shops, services, and a 1,000-car parking garage is a unique feature of the city. For reservations at several hotels that have offered discounts rates, you have but to complete the following:

All hotels below listed are near the Convention Center on the covered Skywalk system.

Guest room bookings at special convention rates are handied on a first-come, first served basis through the Cincinnati Housing Bureau. If your preferred accommodations are not available, they will make reservations at a comparable participating hotel. Telephone reservations are not accepted by the Bureau, but inquiries may be made to (513)621-2119 during Eastern Time business hours. The deadline for returning this form is July 1, 1993. After then, arrangements must be made directly with the hotels, and the quoted rates may not be available.

The Housing Bureau will acknowledge your reservation promptly and the hotel will confirm it separately. One night's rent is required as a deposit to guarantee the reservation. The deposit can be made either by furnishing credit card information on this form or by sending a check directly to the hotel.

To cancel or change reservations before July 1 , write or phone the Housing Bureau. After July 1 , contact the hotel directly. Hotels generally honor refund requests received at least three days before arrival.

\begin{tabular}{llllll} 
& \multicolumn{5}{c}{ Meeting Hotels and Rates } \\
& Single & Double & Triple & Quad. \\
Clarion & $\$ 81$ & $\$ 96$ & & \\
Hyatt & $\$ 92$ & $\$ 102$ & & \\
Omni Netherland & $\$ 91$ & $\$ 111$ & $\$ 131$ & $\$ 151$ \\
Terrace Hilton & $\$ 90$ & $\$ 110$ & &
\end{tabular}

Rates are per night and do not include $10 \%$ Ohio tax

\section{MICROSCOPY SOCIETY OF AMERICA CONFERENCE} Please type or print clearly. Use one form for each room request.
Photocopy additional forms if necessary.

Complete and Mail to:

Cincinnati Housing Bureau 300 West 6th Street Cincinnati, OH 452202

Send confirmation to:

Name:

Mailing Address:

Zip:

Daytime Phone:

Arrival Date:

FAX:

Name(s) of occupants:

Hotel Preference:

1st Choice:

2nd Choice:

3rd Choice:

Type of Room Requested:

_ Single; __ Double; _ Triple; _ Quad.

If you wish to use a major credit card to guarantee your reservation, please supply the following information:

Card Type: Expires:

Card Number:

Cardholder Name (Print):

Cardholder Signature : 